\title{
Hansische Geschichtsblätter
}

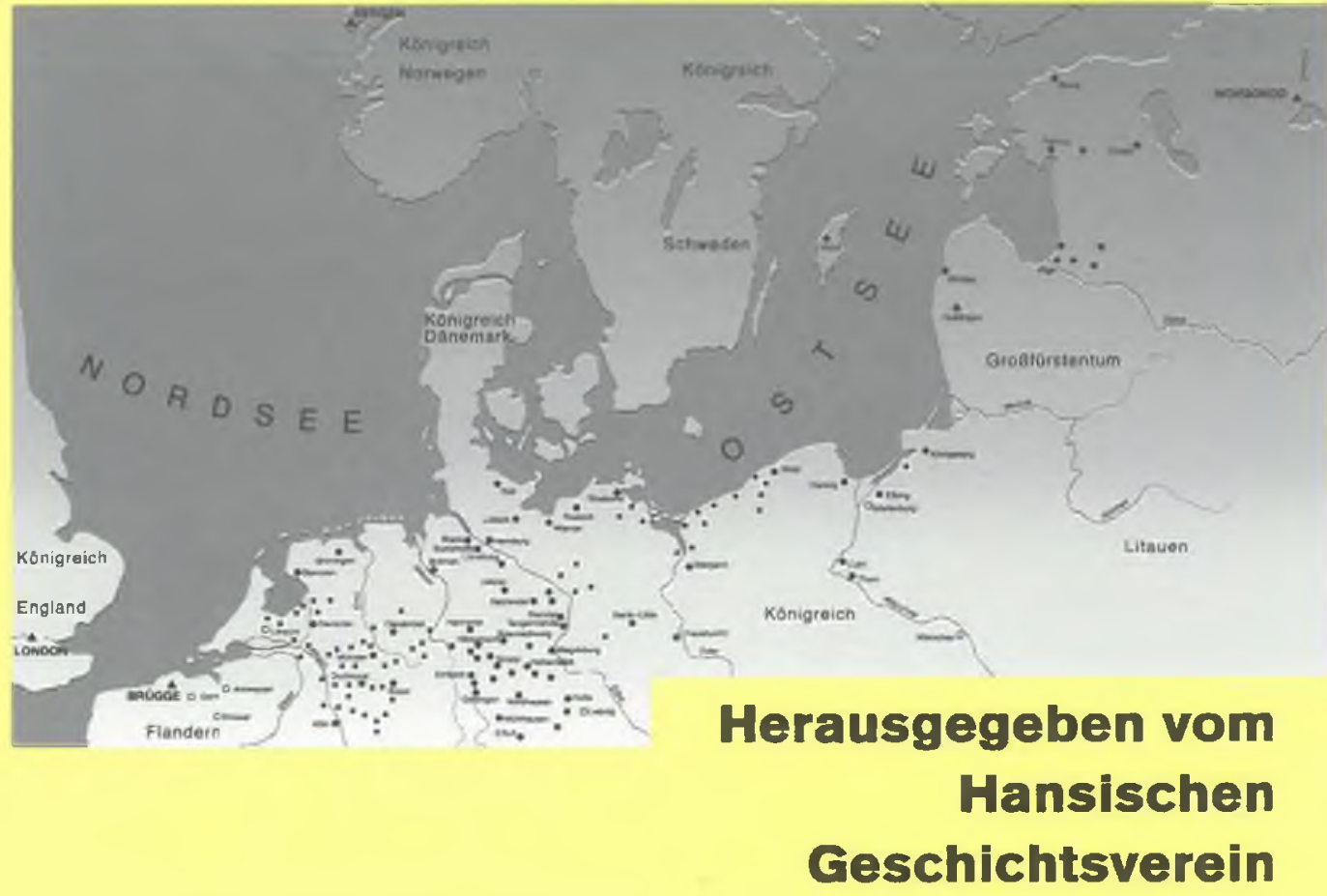

Porta Alba 


\title{
HANSISCHE \\ GESCHICHTSBLÄTTER
}

\author{
HERAUSGEGEBEN \\ VOM \\ HANSISCHEN GESCHICHTSVEREIN \\ 129. JAHRGANG
}

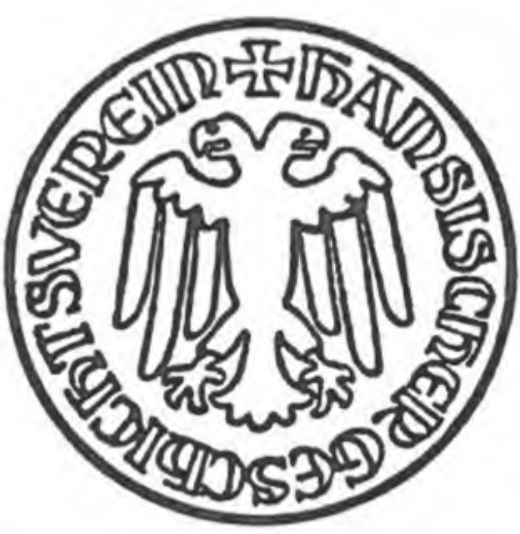

2011

Porta Alba Verlag

Trier 


\section{REDAKTION \\ Aufsatzteil: Prof. Dr. Rolf Hammel-Kiesow, Lübeck \\ Umschau: Dr. Volker Henn, Kordel}

Für besondere Luwendungen und erhöhte Jahresbeiträge, ohne die dieser Band nicht hätte erscheinen können, hat der Hansische Geschichtsverein folgenden Stiftungen, Verbänden und Städten zu danken:

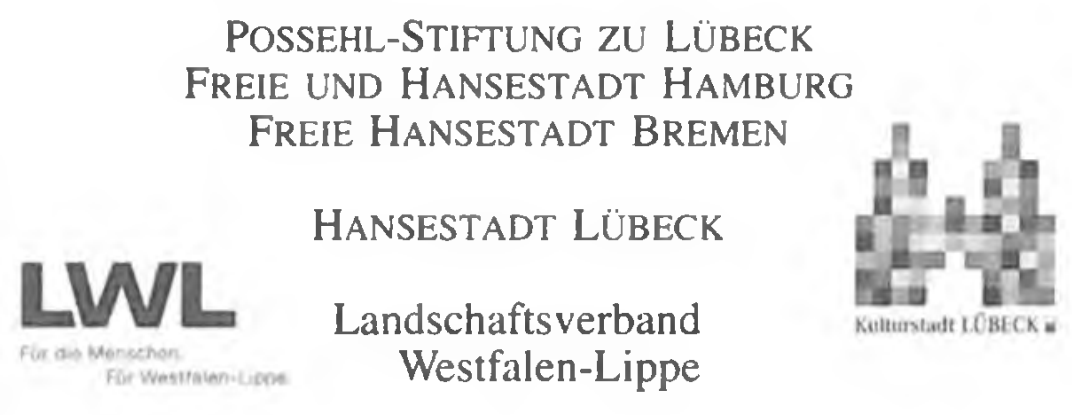

Dr. Margarete Schindler, Buxtehude

Umschlagabbildung nach: Hanseraum und Sächsischer Städtebund im Spätmittelalter, in: Hanse, Städte. Bünde. Die sächsischen Städte zwischen Elbe und Weser, Bd. 1, hg. v. Matthias Puhle, Magdeburg 1996, S. 3.

Zuschriften, die den Aufsatzteil betreffen, sind zu richten an Herrn Prof. Dr. Rolf HAMMEL-KIESOW, Archiv der Hansestadt Lübeck, Mühlendamm 1-3, 23552 Lübeck (rolf.hammel-kiesow@luebeck.de); Besprechungsexemplare und sonstige Zuschriften wegen der Hansischen Umschau an Herrn Dr. Volker HENN, Auf dem Pfahl 5, 54306 Kordel (v.henn@gmx.de).

http://www.hansischergeschichtsverein.de

Beiträge werden als Manuskript und auf Diskette erbeten. Die Verfasser erhalten von Aufsätzen und Miszellen 10, von Beiträgen zur Hansischen Umschau zwei Sonderdrucke unentgeltlich.

Die Lieferung der Hansischen Geschichtsblätter erfolgt auf Gefahr der Empfänger. Kostenlose Nachlieferung in Verlust geratener Sendungen erfolgt nicht.

Die in dieser Zeitschrift veröffentlichten Beiträge sind urheberrechtlich geschützt.

Eintritt in den Hansischen Geschichtsverein ist jederzeit möglich. Der Jahresbeitrag beläuft sich z. Zt. auf $€ 30$ (für in der Ausbildung Begriffene auf $€ 15$ ). Er berechtigt zum kostenlosen Bezug der Hansischen Geschichtsblätter. - Weitere Informationen gibt die Geschäftsstelle im Archiv der Hansestadt Lübeck, Mühlendamm 1-3, 23552 Lübeck. 


\section{HANSE UND REICH \\ REZEPTIONSGESCHICHTE IM 19. UND 20. JAHRHUNDERT}

von Matthias Puhle

Im ersten Band seiner „Geschichte des Hanseatischen Bundes", der 1802 erschien, bezeichnete Georg Sartorius die Hanse als eine „halbvergessene Antiquität".' Zwischen dem letzten Hansetag 1669 und 1802 lagen rund 130 Jahre, in denen die Erinnerung an die Hanse selbst in den Kernstädten derselben stark verblasst war. Im absolutistischen 18. Jahrhundert, in dem sich auch die Stadtbürger als Untertanen des fürstlichen Landesherrn fühlten, war kein Platz für ein Geschichtsbewusstsein, das die Idee der Stadtfreiheit und der Selbstverwaltung der Bürger konservierte.

Die große Veränderung des kollektiven historischen Bewusstseins in Deutschland setzte ab 1806 ein. Das Ende des Heiligen Römischen Reiches, von Kaiser Franz II. am 6. August 1806 verkündet, sowie die Niederlage Preußens bei Jena und Auerstedt im Herbst 1806 wurden von nicht wenigen als die „tiefste Erniedrigung Deutschlands“ empfunden. Die drei verbliebenen Hansestädte Lübeck, Bremen und Hamburg beschworen im Oktober 1806, als wollten sie ein Zeichen gegen die Auflösung des Heiligen Römischen Reiches setzen, die Verbindung, durch die die Städte „seit Jahrhunderten unter dem Namen der Hanse bereits vereinigt, und in solcher Vereinigung anerkannt waren". ${ }^{2}$ Die nun erstarkende und in mancher Beziehung erst entstehende Nationalbewegung brachte einen neuen Typus von Historiographie hervor, die Nationalgeschichtsschreibung. Sehr schnell wurde die Epoche der deutschen Kaiserzeit im Mittelalter idealisiert und neben dem im Nibelungenlied und Hermann dem Cherusker wurzelnden Germanentum sehnsuchtsvoll beschworen und angesichts des als jammervoll empfundenen Zustands Deutschlands, der durch Kleinstaa-

\footnotetext{
' Zit. Nach Volker HenN, Was war die Hanse? S. 14-23, in: Die Hanse. Lebenswirklichkeit und Mythos, hg. von Jörgen Bracker, Volker Henn, Rainer Postel, Lübeck 1998, S. 14.

${ }^{2}$ Zit. nach Michael HuNDT, Von der ,halbvergessene[n] Antiquität“ zum modernen Staatenbund? Bedingungen, Ziele und Wirkungen hanseatischer Politik zwischen Altem Reich und Wiener Ordnung (1795-1815), in: Ausklang und Nachklang der Hanse im 19. und 20. Jahrhundert, hg. von Antjekathrin Graßmann (Hansische Studien 12), Trier 2001, S. 1-30.
} 
terei und nationale Schwäche gekennzeichnet war, im Sinne eines Auftrags an die Gegenwart verstanden. Als nationaler Mythos wurde nun Kaiser Friedrich Barbarossa erkoren.

„Der alte Barbarossa,

Der Kaiser Friedrich,

Im unterirdischen Schlosse

Hält er verzaubert sich [...]

Er hat hinab genommen

Des Reiches Herrlichkeit,

Und wird einst wiederkommen

Mit ihr zu seiner Zeit ${ }^{\star 3}$

Friedrich Rückert

Der ironische Zwischenruf Heinrich Heines, der in „Deutschland ein Wintermärchen“ erklang, konnte an der Barbarossa-Begeisterung wenig ändern:

„Herr Rotbart - rief ich laut - du bist

ein altes Fabelwesen,

Geh, leg dich schlafen, wir werden uns

Auch ohne dich erlösen.

Das beste wäre, du bliebest zu Haus

Hier in dem alten Kyffhäuser -

Bedenk ich die Sache ganz genau,

So brauchen wir gar keinen Kaiser. ${ }^{\text {"4 }}$

Heine blieb mit der Ironisierung des Themas „Kaiser und Reich im Mittelalter" mehr oder weniger allein. 1871 erreichte die Barbarossa-Verehrung mit der Gründung des deutschen Kaiserreichs einen neuen Höhepunkt. Zwei herausragende Historienmonumente wurden in den folgenden Jahren geschaffen, die Kaiser Wilhelm I. als legitimen Nachfolger Friedrich Barbarossas darstellen. Vor der Kaiserpfalz von Goslar, die auf Kosten des Staates prachtvoll wiederhergestellt und mit einem 53 Bilder umfassenden historischen Bilderzyklus von Hermann Wislicenus ausgestattet wurde, reiten der Staufer Friedrich I. und der Hohenzoller Wilhelm I. Seite an Seite. 1890-96 wurde auf dem Kyffhäuser das Kaiser-Wilhelm-Nationaldenkmal errichtet, das die Sage um den wiederkehrenden Barbarossa mit dem Gründer des deutschen Kaiserreichs Wilhelm I. verknüpft.

\footnotetext{
${ }^{3}$ Friedrich RüCKERT, Werke, hg. und mit einer Einleitung versehen von Edgar Gross und Elsa Herzter, Bd. 1, Hildesheim 1979, Nachdruck der Ausgabe Berlin 1910, S. $74 \mathrm{f}$.

${ }^{4}$ Heinrich HEINE, Deutschland. Ein Wintermärchen, in: Heinrich Heines Werke, 1. Bd., Frankfurt/M., 1968.
} 
Barbarossa ist aber nicht die einzige historische Persönlichkeit auf die Kaiser Wilhelm bezogen wird. Im „Bildersaal Deutscher Geschichte“ von 1890, dem Buch, das wahrscheinlich das Geschichtsbewusstsein der Deutschen wie kein anderes prägte, findet sich u. a. das Gemälde „Deutschlands Einigung" von Anton von Werner, das den Handschlag zwischen den alten Germanen und den Preußen zeigt. (Abb. 1)

Die Rezeption der Hanse vollzog sich im Laufe des 19. Jahrhunderts in nicht ganz so intensiver, identitätsstiftender Weise, dennoch ähnlich. Zum Zentrum der wissenschaftlichen Hanse-Rezeption wurde der Hansische Geschichtsverein, der zum 500. Jahrestag des Friedens von Stralsund 1870 gegründet wurde, und die von ihm ab 1871 herausgegebenen Hansischen Geschichtsblätter. Thomas Hill macht jedoch zurecht darauf aufmerksam, dass auch die zu dieser Zeit führenden Hanseforscher, Karl Koppmann und Wilhelm Mantels, nationalliberal gesonnen waren und bei ihren Forschungen nicht nur Wissen über vergangene Epochen, sondern Stolz auf die ruhmreiche deutsche Vergangenheit vermittelten und die Legitimation für politisches Handeln in der Gegenwart gleichsam mitlieferten. So wurde der Stralsunder Frieden von 1370 zum „Vorläufer des deutschen Sieges von 1864 über Dänemark". 5

Die Renaissance der Hanse in der entstehenden Nationalgeschichtsschreibung des 19. Jahrhunderts beruhte einerseits auf dem wissenschaftlichen Bemühen, der Hanse als historischem Phänomen ein quellengesättigtes Fundament zu geben, was die Edition der Hanserezesse und des Hansischen Urkundenbuchs zur Folge hatte, und andererseits, ähnlich wie im Falle der Geschichte des mittelalterlichen Reichs, Stolz und Selbstbewusstsein aus der deutschen Geschichte zu beziehen, um sich über die bis zur Gründung des deutschen Kaiserreichs 1871 als eher demütigend empfundene Rolle Deutschlands im 19. Jahrhundert hinwegtrösten zu können.

Die Hanse konnte hierbei eine besondere Funktion für das Bürgertum spielen, das ja im 19. Jahrhundert trotz steigender ökonomischer Bedeutung in der Adelsgesellschaft Deutschlands von einer entsprechenden politischen Beteiligung noch weit entfernt war. Die Freiheit der mittelalterlichen Stadt, die Selbstverantwortung der Bürger, Rechtsstaatlichkeit, Tüchtigkeit, Wohlstand, das alles verband man - berechtigt oder nicht mit der Hanse und den Hansekaufleuten, die ja zugleich auch Stadtbürger waren. Auf der anderen Seite füllte die Hanse zumindest in einem gewissen Maße die Lücke, die der „Niedergang des Kaisertums" im späten

${ }^{5}$ Thomas HILL, Vom öffentlichen Gebrauch der Hansegeschichte und Hanseforschung im 19. und 20. Jahrhundert, in: Ausklang und Nachklang der Hanse (wie Anm. 2), S. 67-88, S. 76. 


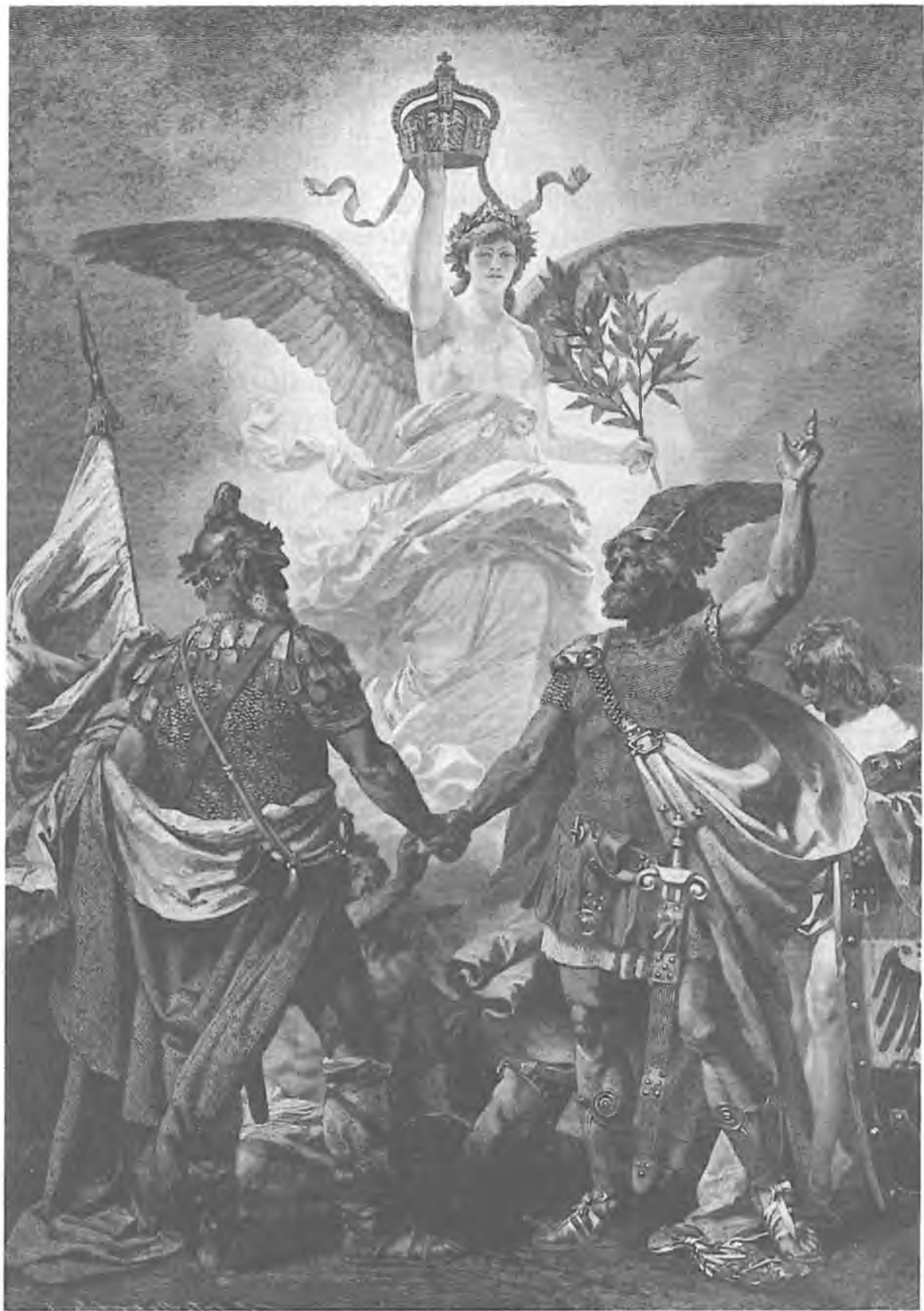

Abb. 1: „Deutschlands Einigung.“ Nach einem Gemälde von A. v. Werner aus „Bildersaal Deutscher Geschichte“ 
Mittelalter hinterließ, sie brachte, um noch einmal Hill zu zitieren ,etwas Glanz in das deutsche Spätmittelalter". 6

Also hatte auch die Hanse, wenn auch in etwas abgemilderter Form gegenüber der Reichsgeschichte, die Aufgabe nationaler Sinnstiftung im 19. Jahrhundert. Gerd Althoff hat nachdrücklich auf diese Wirkung hingewiesen: „Sie (die Sinnstiftung) hat neben anderen Faktoren, die Deutschen mental dazu bereitgemacht, sich Macht, Glanz und Größe zurückzuerobern. Der sehnsüchtige Blick auf die Geschichte, besonders die mittelalterliche, der einstige Größe vorführte, um der Gegenwart einen Auftrag für die Zukunft zu vermitteln, schaffte ein Bewusstsein, das fraglos auch kriegerische Auseinandersetzungen rechtfertigte und beförderte, die bald eine bis dahin unbekannte Größenordnung annahmen und schließlich von einem nie dagewesenen Vernichtungswillen geprägt wurde. Ein böses Diktum sagt über Historiker, im Unterschied zu den ärztlichen täten ihre Fehler niemandem weh: Die Geschichte nationaler Identitätsstiftung in Deutschland ist ein erschreckender Beweis des Gegenteils."7

Die wichtigsten Historiker, die an der nationalen Sinnstiftung im Deutschland des 19. Jahrhunderts arbeiteten, waren nach Althoff Leopold von Ranke, Heinrich von Treitschke, Wilhelm von Giesebrecht und der Kreis junger Gelehrter um die „Jahrbücher für deutsche Geschichte“, darunter Georg Waitz, Rudolf Köpke und Ernst Dümmler. Das borussisch geprägte Geschichtsbild konzentrierte sich auf das mittelalterliche Reich, vor allem die großen Dynastien der Ottonen, Salier und Stauffer mit dem germanischen Vorläufer Arminius, aus dem Hermann wurde, und dem Nibelungenlied. Die spätmittelalterliche Zeit war von Ausnahmen wie der Geschichte der Hanse und der Städte die „Verfallszeit" und ab Mitte des 15. Jahrhunderts regierten fast ausschließlich die Habsburger. Die Habsburger aber waren, wie der einflussreiche preußische Historiker Heinrich von Treitschke feststellte, „undeutsch, egoistisch und reichsfremd“ ${ }^{8}$ Das kleindeutsche, vom Dualismus zwischen Preußen und Österreich geprägte Geschichtsbild, das sich auch im berühmten Sybel-Ficker-Streit letztlich durchsetzte, ließ für die frühe Neuzeit als prägendes Bild nur die Reformation und den sich im Anschluss an den 30igjährigen Krieg vollziehenden Aufstieg Brandenburg-Preußens als europäische Großmacht zu, dessen geschichtliche Mission darin bestand, ,das Reich vom brandenbur-

\footnotetext{
${ }^{6}$ Ebda.

${ }^{7}$ Gerd ALTHOFF (Hg.), Die Deutschen und ihr Mittelalter, Darmstadt 1992, S. 4.

${ }^{8}$ Hans-Ulrich THAMER. Das Heilige Römische Reich als politisches Argument im 19. und 20. Jahrhundert, in: Heiliges Römisches Reich Deutscher Nation 962 bis 1806. Altes Reich und Neue Staaten 1495 bis 1806 - Essays, hg. von Heinz Schilling u. a., Dresden 2006, S. 383-395, S. 391 .
} 
gisch-preußischen Einheitsstaat ausgehend in einen Bund weltlicher Fürsten zu führen".?

Im wilhelminischen Kaiserreich wurde die Hanse im ausbrechenden Ersten Weltkrieg Teil der psychologischen Kriegsführung gegen England. Die Hanse wurde als Argument herangezogen, das die Ebenbürtigkeit Deutschlands mit England zur See historisch belegen sollte. Im Dritten Reich steigerte sich die nationale Sichtweise und die Bedeutungserhöhung der Hanse England gegenüber noch einmal beträchtlich. Danach siegte nach einem etwa gleichgewichtigen Mit- und Gegeneinander der deutschen und der englischen Kaufleute im Mittelalter im 16. Jahrhundert schließlich der englische Protektionismus und der ,rücksichtslose britische Imperialismus", der die Schließung des Hanse-Kontors in London 1598 und damit das faktische Ende des hansischen Handels in England herbeiführte. Die Hanse wurde in den Jahren vor dem Zweiten Weltkrieg und dann vor allem in den ersten Kriegsjahren des Zweiten Weltkriegs wie andere Themen insbesondere des Mittelalters, so z. B. das „Altdeutsche Reich“, wie das „Heilige Römische Reich“ im Dritten Reich genannt wurde, zum Instrument ideologischer Kriegführung des nationalsozialistischen Deutschlands.

Neben Buchveröffentlichungen, Theateraufführungen und Kinofilmen rückte im Dritten Reich das Medium der historischen Sonderausstellung in Museen immer stärker in den Mittelpunkt der Vermittlung historischer Inhalte. Auch die Hanse wurde mehrfach Gegenstand von Ausstellungen, z. B. im Jahr 1939 in Hamburg mit dem Thema „Hamburg und die Deutsche Hanse“. ${ }^{10}$ Diese Ausstellung wurde aus Anlass der 750-Jahrfeier des Hamburger Hafens vom Archiv der Hansestadt Hamburg und dem Museum für Hamburgische Geschichte veranstaltet. (Abb. 2) Interessanterweise gab der 800 . Hafengeburtstag 50 Jahre später, 1989, wieder Anlass zu einer Hanse-Ausstellung in Hamburg.

Der kleine Katalog der Ausstellung von 1939 zeigt, dass auch in dieser hochideologischen Zeit Geschichtsdarstellungen möglich waren, die sich primär an den Schriftquellen und den Objektüberlieferungen orientierten. Die Hanse-Rezeption greift eher auf Haltungen des 19. Jahrhunderts zurück als dass sie Großmachtphantasien des Dritten Reiches kurz vor Ausbruch des 2. Weltkriegs bedient, wenn Erich von Lehe in die Ausstellung mit folgenden Sätzen einführt:

„Als in den Jahrhunderten des späten Mittelalters die Kraft des Ersten Deutschen Reiches sich im Widerstreit vieler Fürsten und Stände zer-

\footnotetext{
${ }^{9}$ Ebda.

${ }^{10} \mathrm{Vgl}$. Hamburg und die Deutsche Hanse, Ausstellung zur Hundertjahrfeier des Vereins für Hamburgische Geschichte und zur 750-Jahrfeier des Hamburger Hafens, Hamburg 1939.
} 
Ardjiv der Ganfeftad Gamburg

Bunte Reibe: 1

\section{amburg und \\ die Deutidye Ganie}

Ausftellung zur Gunderljabrfeier

des Dereins für Gamburgilde Geldidite und zur 750-3ahrfeier des Gamburger Gafens

Veranftaltet vom Ardiviv der Ganfeflad Gamburg und dem Muleum für Gamburgi/dje Ge[didhle

Derzeldnnis zulammengeftellt oon

Erid oon Eebe, Geinrith Reincke, Carl Stbellenberg

Gamburg 1939

Abb. 2: Bucheinband des Katalogs zur Ausstellung „Hamburg und die Deutsche Hanse“, 1939 
splitterte und ein allgemeiner Verfall staatlicher Ordnung eintrat, schlossen sich die aufblühenden Städte in Städtebünden zusammen. Der bedeutendste unter ihnen war der Bund der deutschen Hansestädte." ${ }^{11}$

Die Urkunden, Münzen, Münzstempel, Maße und Gewichte, Tonnenbojen, Stadtgrundrisse, Becher, Büchsen und Pokale, Steinfragmente und Störtebeker-Devotionalien, die in der Ausstellung von 1939 gezeigt wurden, begegneten uns in der Ausstellung von 1989 wieder.

Die Hamburger Ausstellung von 1939 hatte sicher keine besonders groBe nationale Wirkung, sonst hätte sie sich auch kaum in die Nische wissenschaftlicher Dokumentation und gelehrter Argumentation zurückziehen können. Seit 1937 wurde die mittelalterliche Geschichte durch die nationalsozialistische Geschichtspolitik nämlich verstärkt für die Legitimation deutscher Herrschaftsansprüche in Europa herangezogen.

Mit dem Reich des Mittelalters verband sich im Nationalsozialismus die Vorstellung von deutscher Größe, Germanentum und einer aktiven Ostpolitik. Das war in den ersten Jahren der nationalsozialistischen Herrschaft noch nicht so. Die Reichsführung der SS äußerte sich im Jahr 1937 zur „Erschließung des germanischen Erbes“ folgendermaßen:

„Eine der wesentlichsten Perspektiven für die Erschließung des germanischen Erbes ist überhaupt kaum gesehen. Man beschäftigt sich einerseits mit der nationalsozialistischen Wertwelt, andererseits mit dem vorchristlichen Germanentum als dem Urbild dieser Weltanschauung. Die dazwischenliegenden Jahrhunderte, insbesondere das christliche Mittelalter, werden als ein absoluter Bruch gesehen, der die Einheit des deutschen Geschichtsbildes zerstört. Demgegenüber muß hier festgestellt werden. daß ein Vorstoß zu den mittelalterlichen Quellen, namentlich zu den Nachrichten über alle Gegenbewegungen zum Christentum, von unseren weltanschaulichen Erkenntnissen her in einem ungeahnten Maß die germanischen Erbströme erkennen läßt, die sich zwar oft in merkwürdigen Ausprägungen und Umformungen durch die Jahrhunderte schieben. Es wird sich aus dieser Forschungsrichtung eine neue Einheit des germanischen Weltbildes, seine Kontinuität durch alle Jahrhunderte bis in die nationalsozialistische Weltanschauung hinein ergeben. Anders gesagt: der Nationalsozialismus wird hier seine geschichtliche Begründung erhalten, freilich in einer grundlegenden Umwertung fast aller Jahrhunderte und der sie tragenden Erscheinungen." 12

\footnotetext{
${ }^{11}$ Ebda., S. 3.

${ }^{12}$ Nach Jan-Holger KIRSCH, „Wir leben im Zeitalter der endgültigen Auseinandersetzung mit dem Christentum". Nationalsozialistische Projekte für Kirchenneubauten in Enger, Quedlinburg und Braunschweig, in: Widukind. Forschungen zu einem Mythos, hg. von Stefan BRAKENSICK, Bielefeld 1997, S. 33.
} 

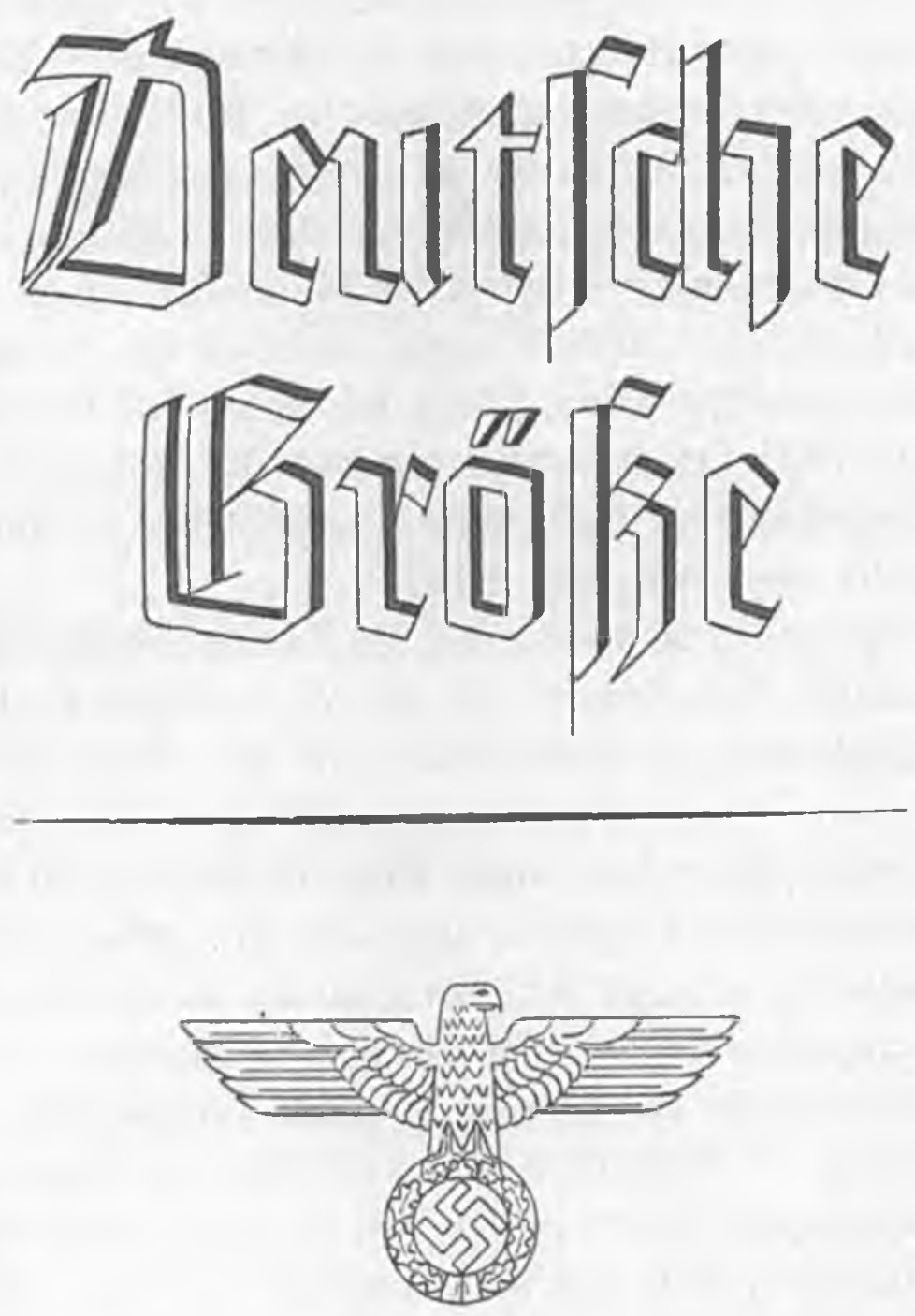

Abb. 3: Bucheinband des Katalogs zur Ausstellung „Deutsche Größe“, 1940/41 
Deutschland im Mittelalter erschien als Schutzmacht, als Vormacht, als Hüter abendländischer Kultur, Bollwerk gegen den asiatischen Osten und Heilsträger Europas. ${ }^{13}$ Die nun ausbrechende Verehrung großer Herrscherpersönlichkeiten des Mittelalters galt zunächst vor allem denjenigen, die nach dem Geschichtsbild der Nationalsozialisten eine aktive Ostpolitik betrieben hatten, also Albrecht dem Bären, Heinrich dem Löwen und vor allem dem von Heinrich Himmler besonders verehrten Heinrich I. Dementsprechend wurden die Grablegen dieser Fürsten in Ballenstedt, Braunschweig und Quedlinburg zu nationalen Weihestätten bzw. Kultstätten umgewandelt. Neben der Errichtung historischer Kultstätten hatten sowohl die historischen Wissenschaften sowie die gesamte Kulturpolitik im Nationalsozialismus die Aufgabe, den Nationalstolz zu fördern und das Dritte Reich als wiederauferstandenes Reich des Mittelalters im Bewusstsein des Volkes zu verankern, das vielleicht sogar imstande sein könnte, die Größe des Alten Reiches zu übertreffen. Einige Historiker wie Hermann Heimpel hatten ja bereits 1933 die „Machtergreifung" der Nationalsozialisten als Wiederherstellung einstiger Bedeutung Deutschlands in Europa gefeiert. „300 Jahre Macht vergessen sich nicht.“14

Viele Historiker sahen sich vor allem im Zweiten Weltkrieg, also in der Zeit der „nationalen Bewährung“, in der Verantwortung, die Herrschaft des Nationalsozialismus zu unterstützen, wie der „Obmann der mittelalterlichen Historiker beim Kriegseinsatz der deutschen Geisteswissenschaften“, Theodor Mayer, auf einer Historikertagung im Februar 1941 ausführte: „Die deutschen Historiker sind sich ihrer Pflicht bewußt, für das zentrale Problem des jetzigen Krieges und der bevorstehenden Neuordnung Europas das geschichtliche Rüstzeug beizubringen und vom Standpunkt der Gegenwart aus die Entwicklung der Vergangenheit zu betrachten und zu deuten." 15 Historiker wie Karl Dietrich Erdmann, Theodor Schieder oder Hermann Aubin, die zu den großen Namen der Historikerzunft in der Bundesrepublik gehörten, machten sich zu Verbündeten der nationalsozialistischen Diktatur. „Geschichte sollte wieder die Lehrmeisterin des deutschen Volkes sein, sie sollte die Leitbilder zur Neuordnung Europas beisteuern, dem Krieg die historischen Weihen verleihen und die „ethnischen Säuberungen“ aus der Vergangenheit heraus sanktionieren. ... In Form von historischer Sinnstiftung lieferten sie die Munition für ein

\footnotetext{
${ }^{13} \mathrm{Vgl}$. Johannes FRIED, Otto der Große, sein Reich und Europa. Vergangenheitsbilder eines Jahrtausends, in: Otto der Große. Magdeburg und Europa, Bd. 1, hg. von Matthias Puhle, Mainz 2001, S. 554f.

${ }^{14}$ Hermann HeIMPEL, Deutsches Mittelalter, Leipzig 1941, S. 29.

${ }^{15}$ Edgar Wolfrum, Geschichte als Waffe. Vom Kaiserreich bis zur Wiedervereinigung, Göttingen ${ }^{2} 2002$. S. 49.
} 


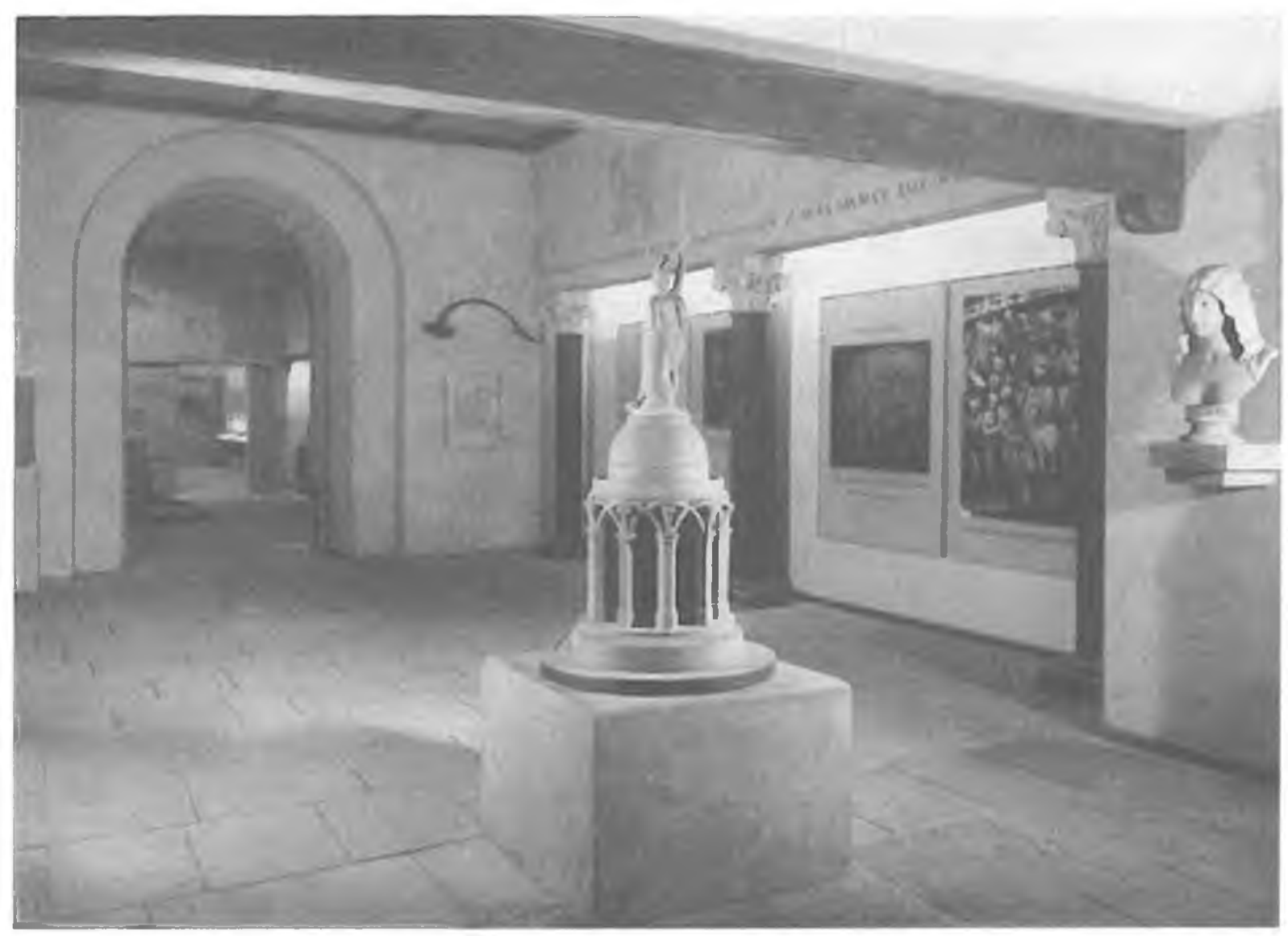

Abb. 4: Raum „Die Germanenreiche“ aus der Ausstellung „Deutsche GröBe“, erschienen in: Die Kunst im Deutschen Reich, Ausgabe A, 5. Jg., Folge 2, 1941

verbrecherisches Regime und dessen Eroberungs- und Vernichtungskrieg. Sie legitimierten den Nationalsozialismus nicht nur, sondern generierten offenbar auch nationalsozialistische Machtphantasien."

Eine ganz wesentliche Rolle in der Geschichtspolitik des Dritten Reiches spielte Alfred Rosenberg, in den zwanziger Jahren Hauptschriftleiter des „Völkischen Beobachters“, seit 1933 Reichsleiter der NSDAP und ab 1934 zugleich „Beauftragter des Führers für die Überwachung der gesamten geistigen und weltanschaulichen Schulung und Erziehung der NSDAP“, dessen Dienststelle kurz „Amt Rosenberg“ genannt wurde, von 1941 bis 1945 Reichsminister für die besetzten Ostgebiete, 1946 in Nürnberg zum Tode verurteilt und hingerichtet. Das „Amt Rosenberg“ verfiel bald auf das Mittel der historischen Ausstellung, um die nationalsozialistische Geschichtsauffassung in der Bevölkerung zu verankern.

Die bedeutendste und eindrucksvollste historische Ausstellung, vom Amt Rosenberg unter der Schirmherrschaft von Rudolf Hess, dem Hitler-

${ }^{16}$ Ebda., S. $47 f$. 
Stellvertreter organisiert, hatte den Titel „Deutsche Größe“. Sie wurde am 8. November $1940 \mathrm{im}$ Deutschen Museum München eröffnet und dann noch an fünf weiteren Orten vor insgesamt 657000 Besuchern gezeigt. (Abb. 3) Die Ausstellung sollte ,dem deutschen Volk Stolz und Selbstvertrauen vermitteln, indem auf die lebensspendende Kraft unserer Geschichte hingewiesen wird. “17

Die Ausstellung „Deutsche Größe" thematisierte deutsche Geschichte von den Germanen bis zum Nationalsozialismus, die ihren Höhepunkt im „Dritten Reich“ fand und den Anspruch Deutschlands auf die beherrschende Rolle in Europa in dem Moment historisch herleiten und begründen sollte, als das „Dritte Reich“ 1940/41 auf dem Zenit seines Eroberungskrieges stand. „Angesichts einer solchen nationalen und volkspädagogischen Ausnahmesituation, in der sich die Historiker und die Deutschen wähnten, war es nicht verwunderlich, dass das Ausstellungskonzept und die Ausstellungsdidaktik diesem ideologischen Geschichtsbild angepasst wurden. Auf authentische Exponate verzichtete man weitgehend; die Repliken, die man statt dessen ausstellte, wurden völlig unabhängig von der tatsächlichen Größe des ursprünglichen Objektes so ausgedehnt, dass sie in das Konzept der Ausstellungsdidaktik passten. Denn im Verständnis der NS-Regisseure zählten bei einer Ausstellung allein Inszenierung und Effekt.“18

Der Begriff „Heiliges Römisches Reich“ wurde in der Ausstellung „Deutsche Größe“ sorgsam vermieden, das Adjektiv „Heilig“ störte schließlich war man ja ,im Zeitalter der endgültigen Auseinandersetzung mit dem Christentum" angekommen - und dass sich dieses Reich bis 1806 als Nachfolger des antiken Römischen Reiches sah und die deutsche Nation nur ein Teil vom Ganzen, wenn auch ein wichtiger war, passte natürlich auch nicht zu der Überbetonung der deutschen Nation in der Ideologie des Nationalsozialismus. Deshalb hieß das „Heilige Römische Reich" des Mittelalters während dieser Periode der deutschen Geschichte „Das altdeutsche Kaiserreich“.

Die Ausstellung „Deutsche Größe" fand in dem Moment statt, als das Dritte Reich seine größte machtpolitische und territoriale Ausdehnung be$\mathrm{saß}$ und die Reichsidee nun vollständig in den Dienst des nationalsozialistischen Geschichtsbildes gestellt wurde. ${ }^{19}$

${ }^{17}$ Karlheinz RüDIGER, Deutsche Größe. Ein Beispiel künstlerischer Ausstellungsgestaltung, S. 36-43, in: Die Kunst im Deutschen Reich, Ausgabe A, 5. Jg., Folge 2, 1941, S. 36.

${ }^{18}$ Thamer, Das Heilige Römische Reich (wie Anm. 8), S. 394; vgl. auch Hans-Ulrich Thamer, Geschichte und Propaganda. Kulturhistorische Ausstellungen in der NS-Zeit, in: Geschichte und Gesellschaft, 24, 1998, S. 349-381.

${ }^{19}$ Vgl. Thamer, Das Heilige Römische Reich (wie Anm. 8), S. 394. 


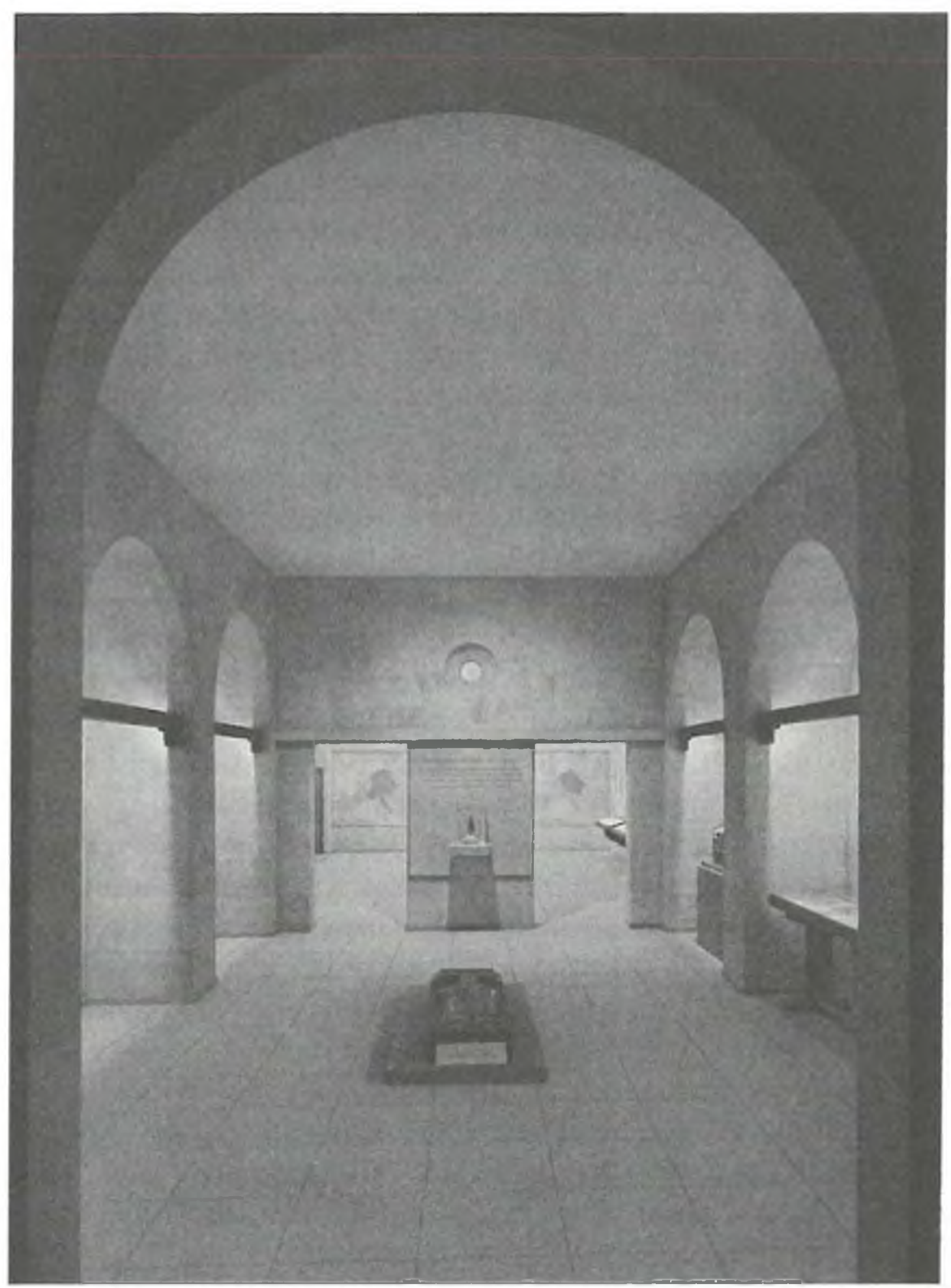

Abb. 5: Abguss des Grabmals des Herzogs Widukind († 807) in der Kirche zu Enger in Westfalen, Nürnberg, Germanisches Nationalmuseum. Raum „Fränkisches Reich“ aus der Ausstellung „Deutsche Größe“, erschienen in: Die Kunst im Deutschen Reich, Ausgabe A, 5. Jg., Folge 2, 1941 
Die Funktion von Geschichte als Legitimation des eigenen Systems wird in dieser Ausstellung ganz deutlich. (Abb. 4-7).

Die Schrifttafel zum Raum mit dem Magdeburger Reiter (Abb. 7) lautet: $^{20}$ „,Kaiserliches Reiterstandbild auf dem Markt in Magdeburg, um 1250. Nachbildung. Das herrliche Bildwerk ist ein ritterliches Sinnbild des deutschen Kaisertums. Es steht auf dem Boden der Stadt, von der aus deutsche Ritter und Kolonisten gen Ostland ritten. In diesem Standbild sehen wir ein Symbol der Kaiserherrlichkeit und Macht Ottos des Großen, des Gründers Magdeburgs. Sein Werk war: Die Schaffung eines deutschen Einheitsstaates auf dem Boden der Lehensverfassung, die Verbundenheit Italiens mit Deutschland, die Unterwerfung des Papsttums und die Erlangung der Kaiserkrone, die Germanisierung des slawischen Ostraums.“

Das sechste der insgesamt 16 Kapitel der Ausstellung widmet sich dem Thema: „Der deutsche Osten. Die Hanse - Der Deutschritterorden“. (Abb. 8) „Ostaufgaben“, so beschreibt es der Katalog, „,sind dem deutschen Volke seit den Tagen Karls des Großen gestellt worden. ... Orden und Hanse verrichteten ihre aufbauende, auch Werke edelster künstlerischer Kultur erzeugende Arbeit, als das Deutsche Reich als solches immer schwächer wurde. Es war die Zeit, als sich in den trüben Zeiten des Interregnums (1250-1273) der verhängnisvolle Brauch herausgebildet hatte, dass eine Gruppe deutscher Fürsten, die „Kurfürsten“, über das Königtum verfügen konnten.“ „Es ist ein Ruhmesblatt des deutschen Kaufmannes dieser Zeit, dass er nicht in privatwirtschaftlichem Denken befangen war, sondern dass er sein wagendes Handeln auf dem Gebiet der Wirtschaft einer einheitlichen, auf einen großen Raum sich erstreckenden Planung unterordnete und einen bewusst deutschen Wirtschaftsaufbau trieb."

Die Exponate der Ausstellung bestanden aus einigen Originalen, Modellen, Karten und Plänen, Fotografien und Skulpturenrepliken. In den Vitrinen befanden sich offenbar eine Reihe von Originalurkunden etwa aus Breslau, Krakau, Wien, Nürnberg oder München. Sie beinhalteten Rechtssprüche des Magdeburger Rechts, Schöffenbriefe aus Magdeburg, Handelsprivilegien, Gründungsurkunden und Insignien der Universitäten Wien und Heidelberg, die „Goldene Bulle“, die „Kulmer Handfeste“ aus Danzig, den Reichsfreiheitsbrief für Lübeck von 1226. Auf dem Bild (Abb. 8) erkennt man in der Mitte ein kleines Koggenmodell und auf der rechten Seite in Nachbildungen der Skulpturen von den Meistern Hartmann und Hans Multscher vom Rathaus zu Ulm, Karl den Großen und die sieben Kurfürsten des Heiligen Römischen Reiches.

${ }^{20}$ Texte aus dem Katalog zur Ausstellung „Deutsche Größe“, Berlin ${ }^{3} 1940 / 41$. 


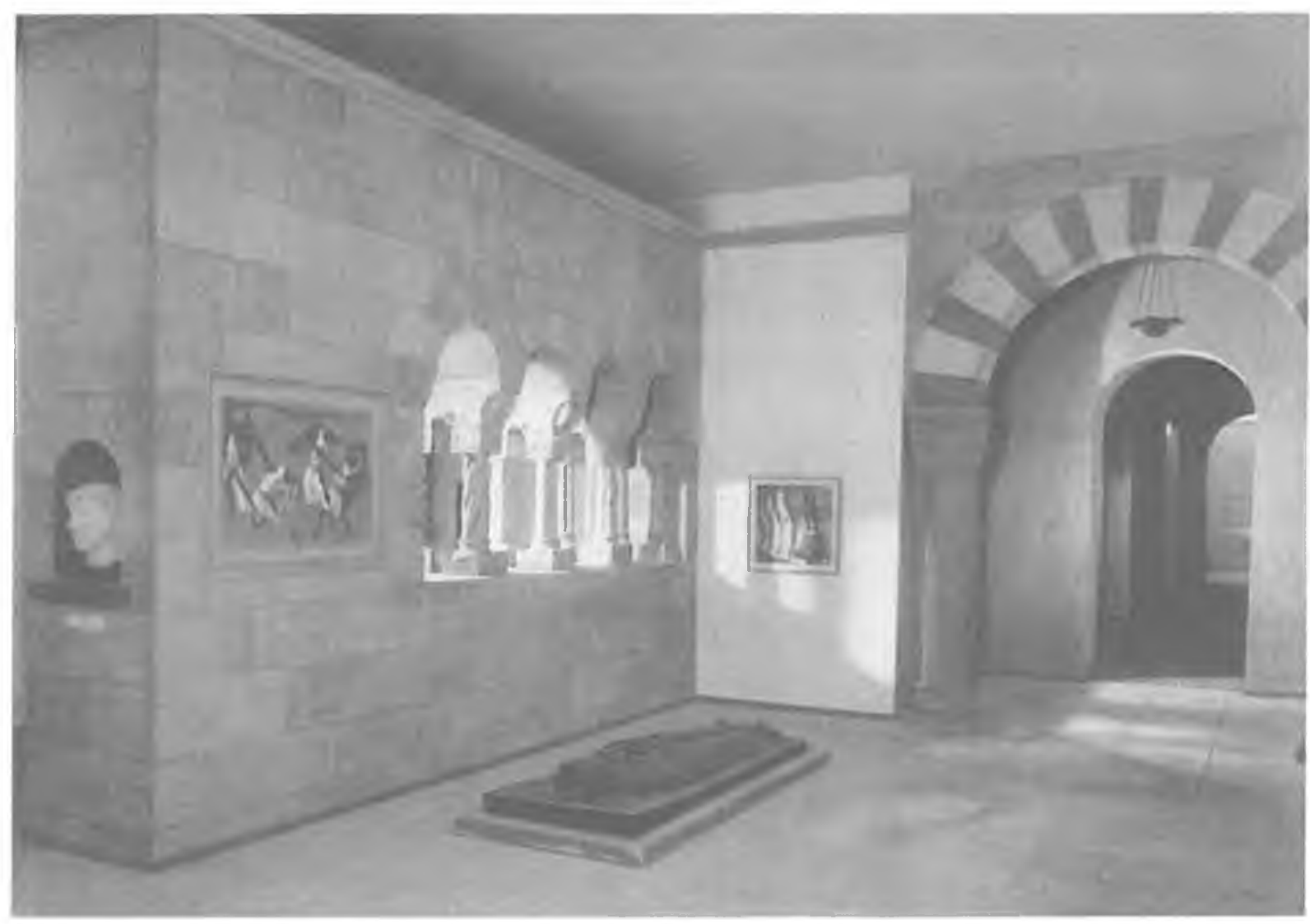

Abb. 6: Raum „Das Altdeutsche Kaiserreich: Die Zeit der Staufer“ aus der Ausstellung „Deutsche Größe“, erschienen in: Die Kunst im Deutschen Reich, Ausgabe A, 5. Jg., Folge 2, 1941

Ausstellungstechnisch zieht die Ausstellung „Deutsche Größe“ alle Register der Ausstellungsgestaltung und -ästhetik, die auch uns Heutigen in modernen Präsentationen nicht unvertraut sind.

Zum 15. und letzten Kapitel der Ausstellung „Das grossdeutsche Reich Adolf Hitlers" heißt es u. a.: „Zweitausend Jahre deutscher Geschichte sind verstrichen, bis das deutsche Volk sich im nationalsozialistischen großdeutschen Volksstaat zusammenfindet. Armin der Cherusker vereinigte die verschiedenen germanischen Stämme und besiegt [sic!] die Römer. Es gelingt ihm jedoch nicht, die Germanen auf die Dauer unter einheitlicher Führung zu halten. Karl der Große errichtet das erste große germanische Kaiserreich. Die Reichseinheit der germanischen Stämme wird durch das Schwert und den Einsatz der Kirche Roms erzwungen. Die Staufer errichten das größte Kaiserreich des Abendlandes und schenken der Christenheit ein Weltbild voll Macht und Größe. Das Reich umschließt verschiedene Nationen. Die Staufer scheitern in Italien. Durch ihren Untergang wird der Weg zum Anstieg der französischen Vormachtstellung in Europa vorbereitet. 


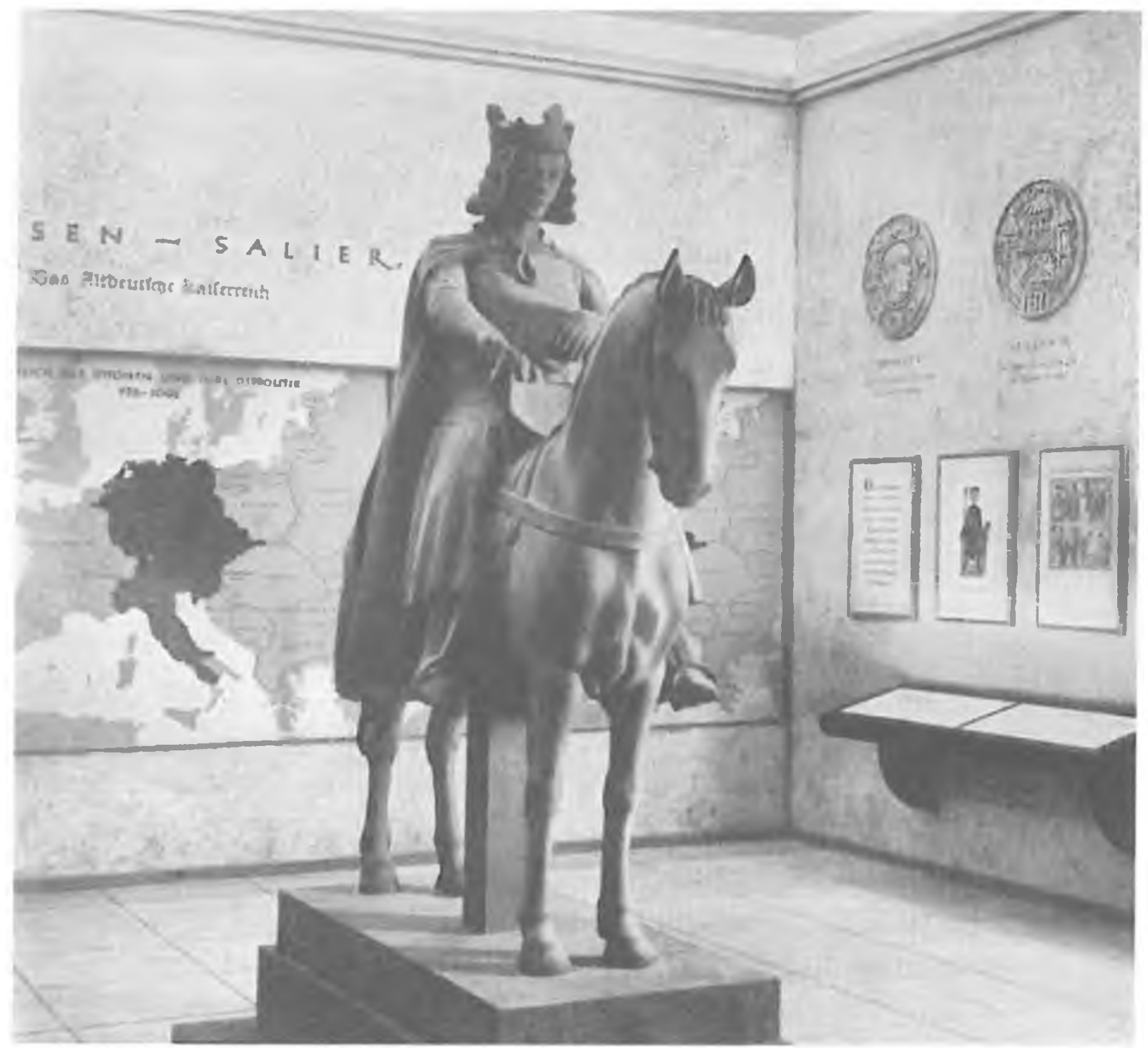

Abb. 7: Raum „Das Altdeutsche Kaiserreich: Die Zeit der Sachsen und Salier“" aus der Ausstellung „Deutsche Größe“, erschienen in: Die Kunst im Deutschen Reich, Ausgabe A, 5. Jg., Folge 2, 1941

Friedrich der Große wird der mächtigste König unter den Landesfürsten. Sein Kampf um Preußen führt zu einer Vorstufe des neuen Großdeutschen Reiches.

Bismarck eint in Versailles die deutschen Bundesfürsten zu einem noch kleindeutschen Reich unter Führung Preußens.“

Hermann der Cherusker - Karl der Große - Friedrich der Große Bismarck - Hitler. Die 2000jährige Geschichte Deutschlands war ein langer Weg voller Irrungen und Wirrungen zu sich selbst, unter Hitler erfüllte sich das Schicksal Deutschlands. Auf diesem Geschichtsbild des Dritten Reiches entwickelte sich ab Ende des Zweiten Weltkriegs die These vom deutschen Sonderweg, als von dem Weg Deutschlands in den Nationalsozialismus, der schon tief in der Geschichte angelegt war. Französische, 


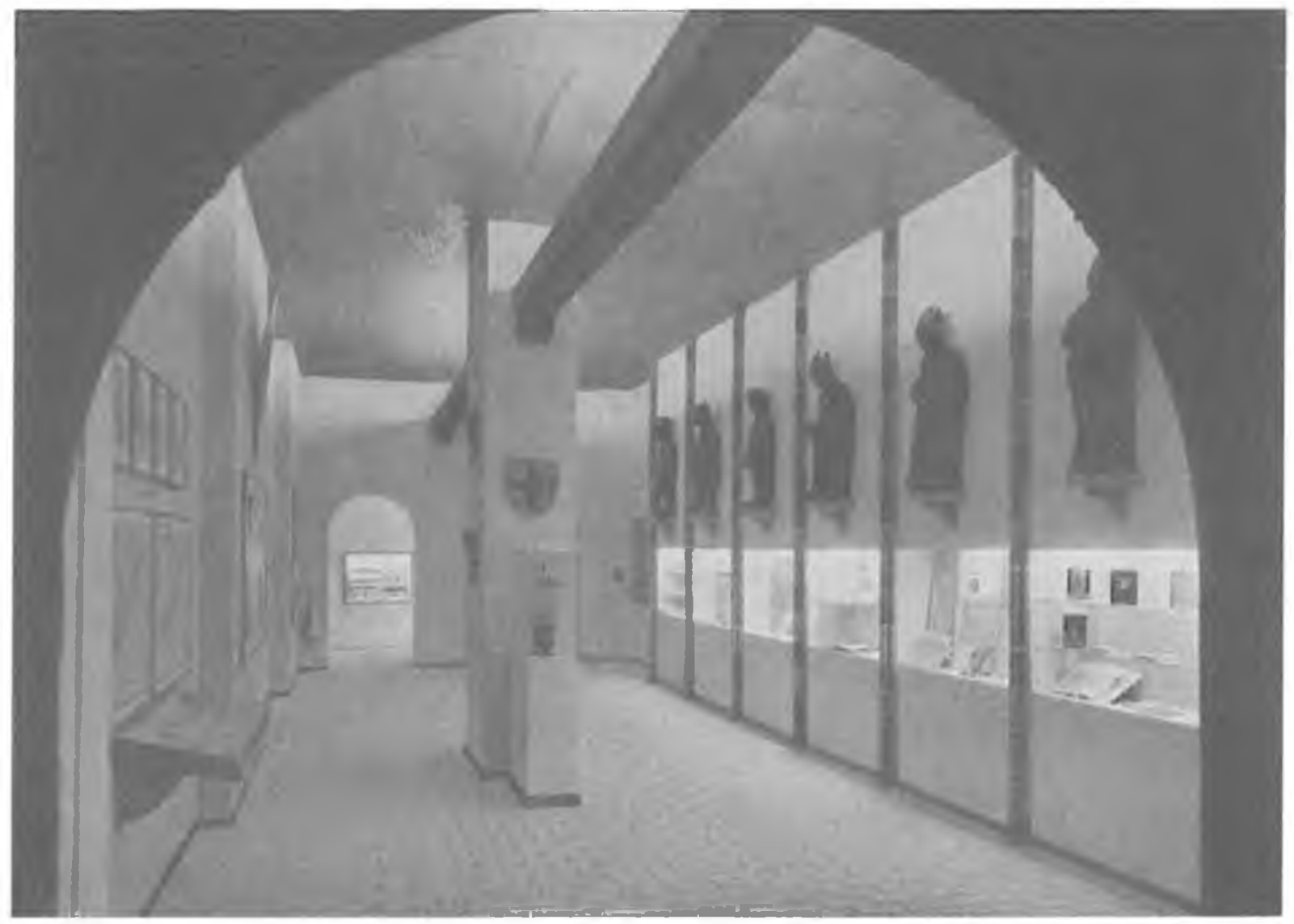

Abb. 8: Raum „Der Deutsche Osten, Hanse und Deutschritterorden“ aus der Ausstellung „Deutsche Größe“, erschienen in: Die Kunst im Deutschen Reich, Ausgabe A, 5. Jg., Folge 2, 1941

englische und amerikanische Historiker vertraten diese These in besonderer Weise.

Hitler, das sollte die Ausstellung „Deutsche Größe“ zeigen, war der legitime Erbe der Kaiser des Mittelalters. So heißt es im Schlusswort:

„Adolf Hitler steht am Eingang eines Zeitalters, das er heute schon durch seine Taten bestimmt, die erkennen lassen, daß wir wieder einer Einheit zustreben, die von innen heraus mit einer neuen Haltung das Erbe der großen Kaiserreiche des Mittelalters antritt.“

Aus diesem Grund wurde nach 1945 der Geschichte eine Art Mitschuld an der „Machtergreifung“ des Nationalsozialismus 1933 und seinen Eroberungsplänen gegeben. So gerieten die großen Themen deutscher Geschichte für eine Reihe von Jahren an den Rand des gesellschaftlichen Interesses in Deutschland.

Die historische Forschung nahm aber bald wieder ihre Arbeit auf, und zwar im Falle der Hanse-Forschung trotz der deutschen Teilung gleichsam gesamtdeutsch im Hansischen Geschichtsverein, der seit 1870 den Kristallationskern der Forschung zur Hanse bildet. Besonders die jährlich erscheinenden Hansischen Geschichtsblätter stellen bis heute das Forum der 


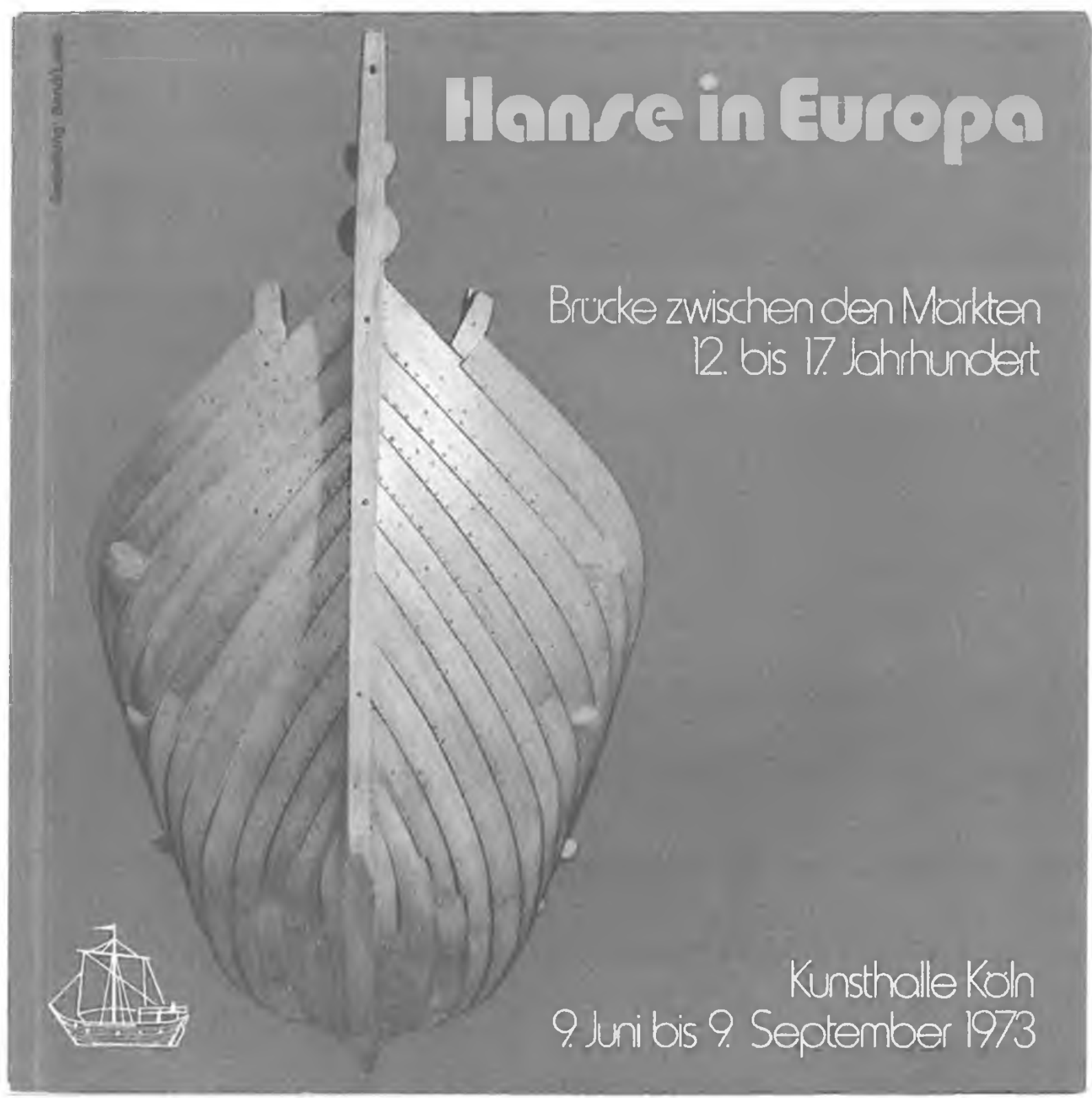

Abb. 9: Bucheinband des Katalogs zur Ausstellung „Hanse in Europa“, Köln 1973

hansischen Geschichte dar. Bis 1970 waren west- und ostdeutsche Historiker gemeinsam Mitglieder im Hansischen Geschichtsverein. 1970 kam es zur Trennung. Die Hanse-Historiker der DDR mussten schon zuvor ihre „Hansische Arbeitsgemeinschaft“ als eine Abteilung der „Gesellschaft der Historiker der DDR“" neu organisieren.

Als wesentliche Unterschiede der Hanse-Forschung in beiden deutschen Staaten fallen neben der grundsätzlichen Ausrichtung der Geschichtswissenschaft, die in der Zeit der Teilung ganz allgemein als „bürgerliche Geschichtsschreibung“ im Westen der „marxistischen“ im Osten gegenüberstand, folgende drei wesentliche Unterschiede auf: 


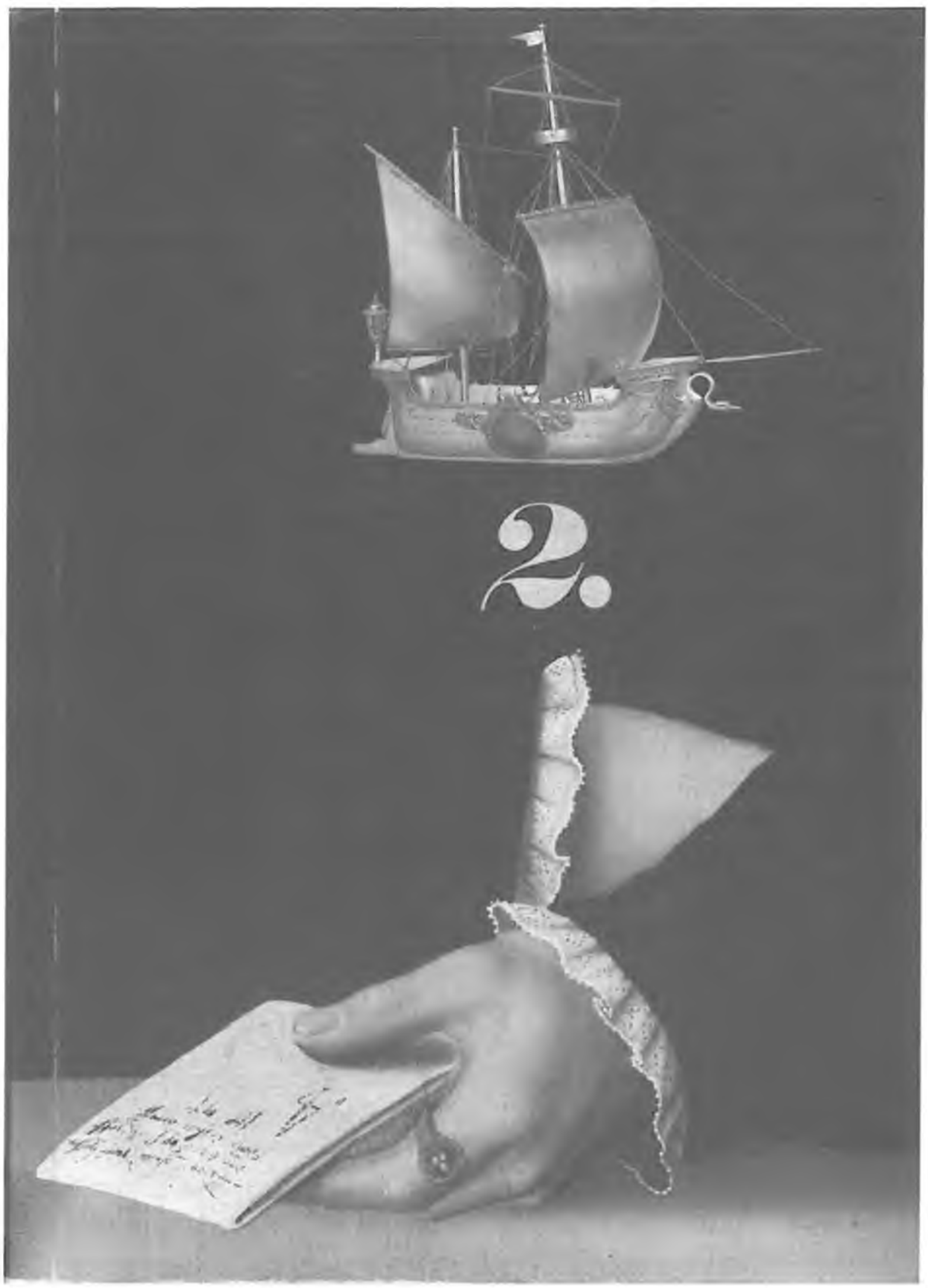

Abb. 10: Bucheinband des Katalogs zur Ausstellung „Die Hanse“, Hamburg 1989 
1. In der DDR-Forschung wurde die Hanse ganz deutlich als „Städtebund“ bezeichnet. Hierbei war die Frage der rechtlichen Kriterien, die bei den westdeutschen Historikern so wichtig war, nicht so wesentlich. Es kam auf die tatsächliche ökonomische und politische Wirksamkeit an. Die westdeutsche Forschung bevorzugte den Begriff „Interessengemeinschaft" oder ähnliche Begriffe, um deutlich zu machen, dass es sich bei der Hanse um einen relativ lockeren Verbund von Städten und Kaufleuten handelte.

2. Die DDR-Forschung betonte stets den Vorrang der ökonomischen Bedeutung der Hanse, die die politische Herrschaft der Kaufleute sichern sollte. Für die westdeutsche Forschung bildete das ,pluralistische“ Zusammenwirken vieler verschiedener Faktoren die Grundlage für das Handeln der Hanse.

3. Die Städteunruhen des späten Mittelalters hat die DDR-Forschung als wesentlichen Bestandteil der frühbürgerlichen Revolution und der hansischen Geschichte angesehen, während die westdeutsche Hanse-Forschung, von Ausnahmen abgesehen, sich nur dann für diese Unruhen interessierte, wenn es Reaktionen der Hanse darauf gab.

Insgesamt waren jedoch die Unterschiede in der Hanseforschung zwischen West und Ost eher geringfügig. Man hat rückblickend fast den Eindruck, als hätte man angesichts all der Übereinstimmungen dringend irgendetwas Trennendes gesucht.

Nach der Wiedervereinigung 1990 wurden die Hanse-Historiker der DDR in den Hansischen Geschichtsverein aufgenommen und die Hansische Arbeitsgemeinschaft aufgelöst. Insgesamt wird die Hanse nach 1945 im Rahmen der europäischen Einigung immer stärker als eine Organisation wahrgenommen, die den ,nationalen“ Rahmen sprengte und schon im Mittelalter europäische Dimensionen annahm.

Ganz deutlich wurde die identitätsstiftende Wirkung der Hanse für Europa in der Kölner Ausstellung „Hanse in Europa. Brücke zwischen den Märkten. 12.-17. Jahrhundert" von 1973 herausgearbeitet. (Abb. 9) Weitere Ausstellungen in Hamburg und Rostock (Abb. 10) sowie Magdeburg in den achtziger und neunziger-Jahren des 20. Jahrhunderts folgten. (Abb. 11) Diese haben gezeigt, dass die Hanse als historisches Phänomen für das heutige Europa hochaktuell ist und sich hervorragend eignet, das kulturelle Zusammenwachsen der Staaten Europas zu fördern.

Man kann also feststellen, dass die „Hanse“ als ein überaus positiv besetzter Begriff die Zeit extensiver politischer Instrumentalisierung so gut wie unbeschadet überstanden hat und sich als Teil des aktuellen und zukünftigen europäischen Geschichtsbewusstseins glänzend eignet - wobei 


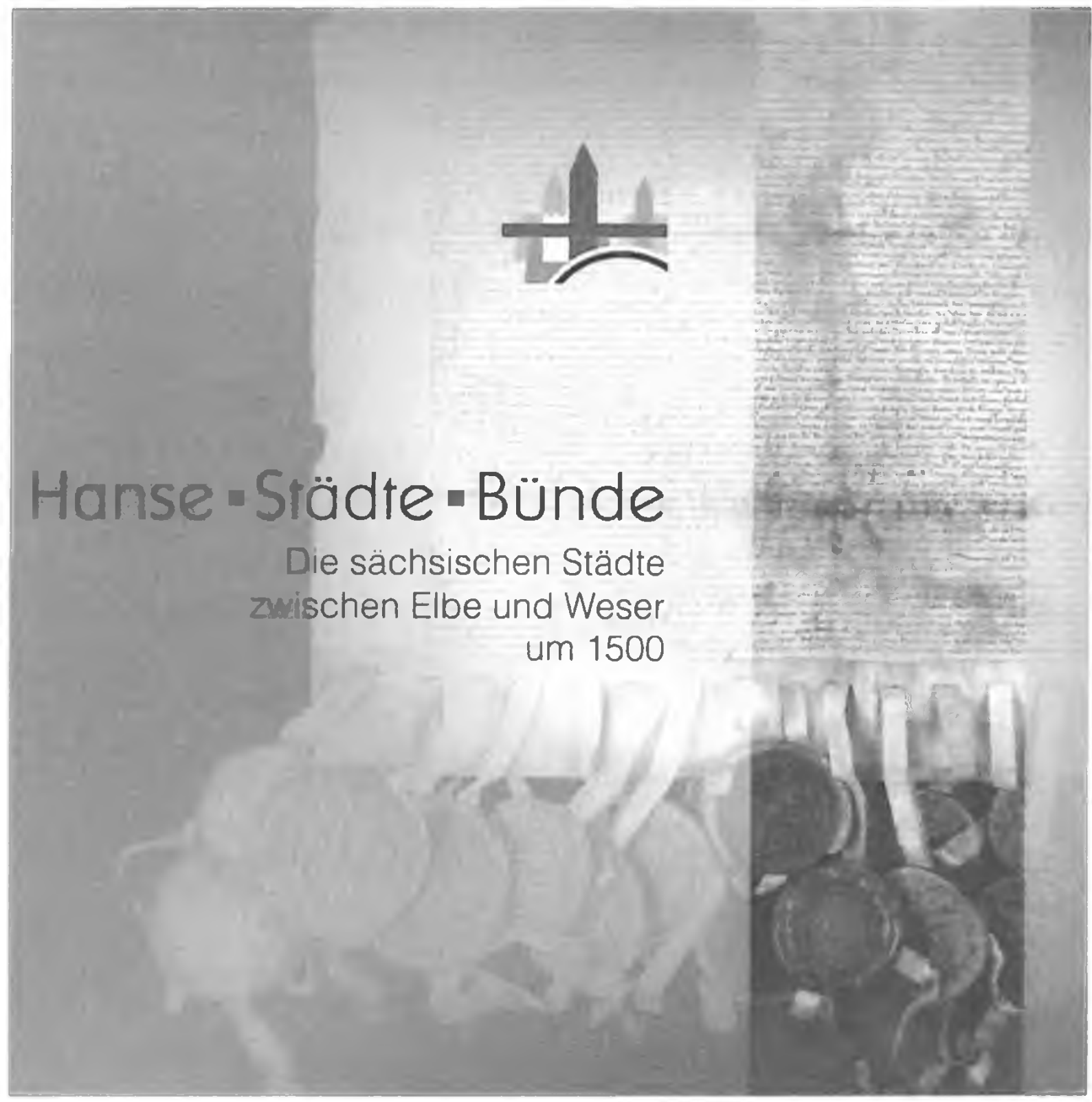

Abb. 11: Bucheinband des Katalogs zur Ausstellung „Hanse - Städte Bünde“, Magdeburg 1996

anzumerken ist, dass auch dies, selbstverständlich, eine politische Instrumentalisierung ist. Für das Ansehen der Hanse-Forschung und den Umgang mit der Hanse ist es gut, dass sich „Reich“ und „Hanse“ in der öffentlichen Wahrnehmung längst entkoppelt haben, denn der Begriff „Reich“ ist im Gegensatz zum Begriff „Hanse“ wesentlich stärker vom Nationalsozialismus missbraucht worden. An der Gründung des Hansetags der Neuzeit 1980 in Zwolle und den boomenden Jahresveranstaltungen der „,neuen Hanse“ ist die Attraktivität des Themas „Hanse“ in unserem Europa von heute gut ablesbar. 